\title{
Asymmetric Synthesis of 1,1-Diarylethane Drugs
}

Synthesis of Natural

Products and

Potential Drugs

Key words

asymmetric addition chiral chaperones

nickel-catalyzed cross-coupling

arylzinc reagents

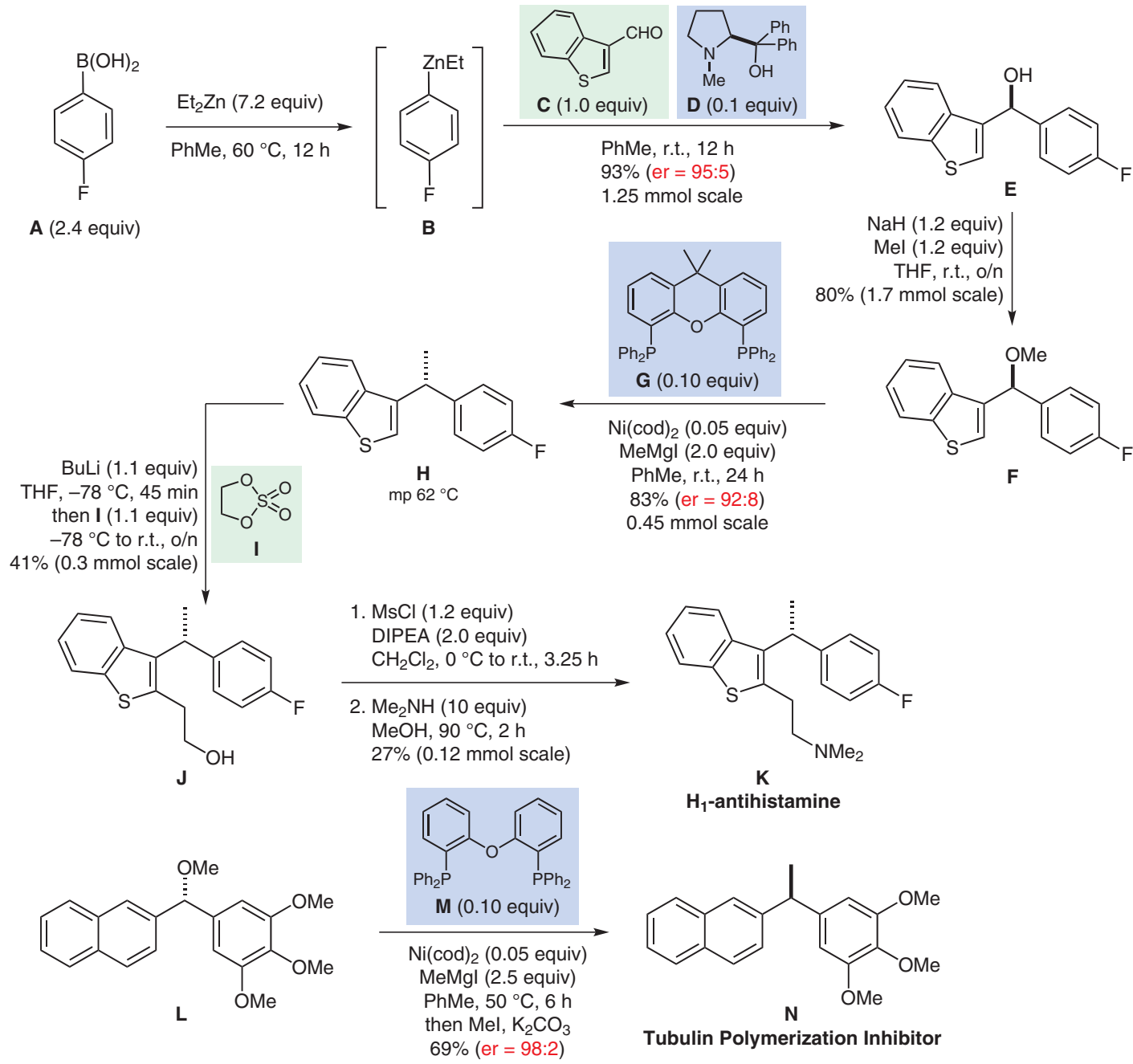

Significance: Syntheses of the sleep-inducing $\mathrm{H}_{1}$-antihistamine $\mathbf{K}$ and the tubulin polymerization inhibitor $\mathbf{N}$ exemplify a general enantioselective synthesis of 1,1-diarylethanes using the stereospecific nickel-catalyzed cross-coupling reactions of alkyl ethers with methylmagnesium iodide. Further seven examples are reported giving yields of $70-96 \%$ and ee values of $85-99 \%$.
Comment: The chiral diarylcarbinols (for example, E) were constructed via enantioselective addition of $\mathrm{Et}_{2} \mathrm{Zn}$ to aryl aldehydes catalyzed by $\mathrm{Ti}(\mathrm{O} \mathrm{i}-\mathrm{Pr})_{4}$ and ent-BINOL (A. S. C. Chan and co-workers Tetrahedron: Asymmetry 1997, 8, 585) or by addition of arylzinc reagents catalyzed by ent-(1-methylpyrrolidin-2-yl)diphenylmethanol (A. L. Braga et al. J. Org. Chem. 2008, 73, 2879).

SYNFACTS Contributors: Philip Kocienski

Synfacts 2011, 4, 0351-0351 Published online: 18.03.2011

DoI: 10.1055/s-0030-1259592; Reg-No.: K01011SF 